\title{
Distillation Assisted by Microwave for Extracting Essential Oil from Java Cananga Flowers
}

\author{
M. Mahfud ${ }^{1}$, A. Chandra K. F. ${ }^{1}$, L. Qadariyah $^{1} \&$ P. Prihatini ${ }^{1}$ \\ ${ }^{1}$ Chemical Process Laboratory, Department of Chemical Engineering, Sepuluh Nopember Institute of \\ Technology, Indonesia \\ Correspondence: M. Mahfud, Chemical Process Laboratory, Department of Chemical Engineering, Sepuluh \\ Nopember Institute of Technology, Surabaya, 60111, Indonesia. E-mail: mahfud@chem-eng.its.ac.id
}

Received: May 4, 2015

doi:10.5539/mas.v9n7p199
Accepted: June 5, 2015

Online Published: June 30, 2015

\begin{abstract}
Cananga oil is one type of essential oil that called etheric oil or light oil. To increase the production of cananga oil, it is need to improve distillation methods and operating conditions, so that extraction process can produce cananga oil more efficient. The aims of this research are to study several factors that influence the distillation methods assisted by microwave, i.e.: flowers conditions, extraction time, mass of material, and microwave power. The experiment was conducted in a round bottom flask distiller that was placed inside a microwave oven and equipped with a Liebig condenser. The operating variables are: flowers conditions (fresh, wilted, chopped). The content of distiller $(100,150,200$ gr). The results of this research shows that the yield of fresh flowers $(0.6251$ $1.1965 \%)$ were higher than wilted flowers $(0.5391-1.0755 \%)$. The mass ratio of material by volume of distillation flask influences on yield obtained. The denser of material, the less of oil yield be obtained. The oil yield increase with time extraction, microwave power and temperature. The distillation assisted by microwave is more efficient than conventional distillation, because we can increase the oil yield with shorter extraction time. The quality of cananga oil obtained by distillation assisted by microwave is conforming to quality standard of Indonesian (SNI) and Essential Oil Association (EOA).
\end{abstract}

Keywords: cananga oil, hydro distillation, steam-hydro distillation, microwave

\section{Introduction}

Indonesia is rich in a wide variety of natural resources. Among of them, there is a variety of plant that can produce important essential oils, which until now has not been fully exploited. Of the 80 types of essential oils traded in the world, Indonesia has only producing and exporting about 15 types of essential oils, such as patchouli oil, Java cananga oil, clove oil, cajuput oil, vetiver oil, nutmeg oil, ginger oil, pepper oil, lemongrass, sandalwood and agarwood oil (Dalimarta, 2000). Until now, Indonesia is the largest world supplier of patchouli oil and Java cananga oil. According to data from the Council of Essential Indonesia, the total value of exports of essential oils reaches 42 million $\mathrm{kg}$ in 2004. Despite the portion of cananga oil accounted for only $5 \%$ of the total exports of essential oils, but his request was never subsided until now (Anonymous, 2006).

Indonesia was also famous as Java Cananga Oil that was actively participating in the International Conference on Essential Oils in Montreal, Canada in 2008. At this time the regions producing of cananga oils are Blitar, Tuban, Purwodadi and Boyolali (Anonymous, 2006). Cananga farming and mastery of refining technology should be improved in order to cananga oil business is able to evolve to fulfil the world needs and can maintain the competitiveness among other countries suppliers. Several factors affect the quality of cananga oils in general are: cananga leaves conditions, methods of distillation, packaging and storage of cananga oil produced. Cananga oil quality is also affected by cultivation techniques, harvesting, drying and storage duration after drying (Hernani, 2006).

Cananga oil distillation process that has been carried out by the refiners in Blitar and Purwodadi, done by hydro distillation, which an amount of cananga flowers are put in a tank filled with water and then boiled using wood fuel, the resulting vapor is condensed in order to obtain a mixture of oil and water, which is then carried out the separation. Through this method, the obtained yield of about $1 \%$, but this process takes a very long distillation time (50-72 hours). Therefore, it is necessary to use other methods considered in the extraction of essential oil to make it faster and get greater oil yield and oil quality that meets SNI or EOA standards. Until now, new 
technology to extract the essential oils has been developed, using microwave heating.

Previous authors has shown that extraction with microwave devices is an alternative that could be developed than the conventional method, due to the high levels of product purity, lack of solvent usage, and short processing time (Ferhat, 2006). These have developed is microwave hydro distillation method, which is a combination of water distillation with microwave heating (Stashenko, 2004;Golmakani, 2008).

Cananga oil is potentially extracted by microwave heating car the microwave devices has been available commercially. It is however necessary to investigate the extraction of cananga flower with microwave heating. The aims of this study was to analyze the effect of the use of microwaves in the distillation process cananga flowers on yield and quality ylang oil produced.

\section{Method}

The sketch of experimental apparatus is shown in Figure 1. The main apparatus contains one liter of three-neck flask made of Pyrex glass functioned as distiller were placed inside the microwave. The outlet of distiller is connected to a Liebig condenser and funnel separator for separating oil and water. The Microwave used is a commercial microwave with the following specifications: Electrolux EMM2007X models, Power output maximum $800 \mathrm{~W}$, Frequency Magnetron $2.45 \mathrm{GHz}, 45 \mathrm{~cm}$ length, $30 \mathrm{~cm}$ width and $25 \mathrm{~cm}$ height.

The raw material of cananga flower (cananga odorata) is obtained from Purwodadi, Pasuruan. Fresh flowers are then stored in the refrigerator to maintain freshness. Most flowers are used directly as raw material distiller and some flowers cut into pieces with a size of approximately $2 \mathrm{~cm}$.

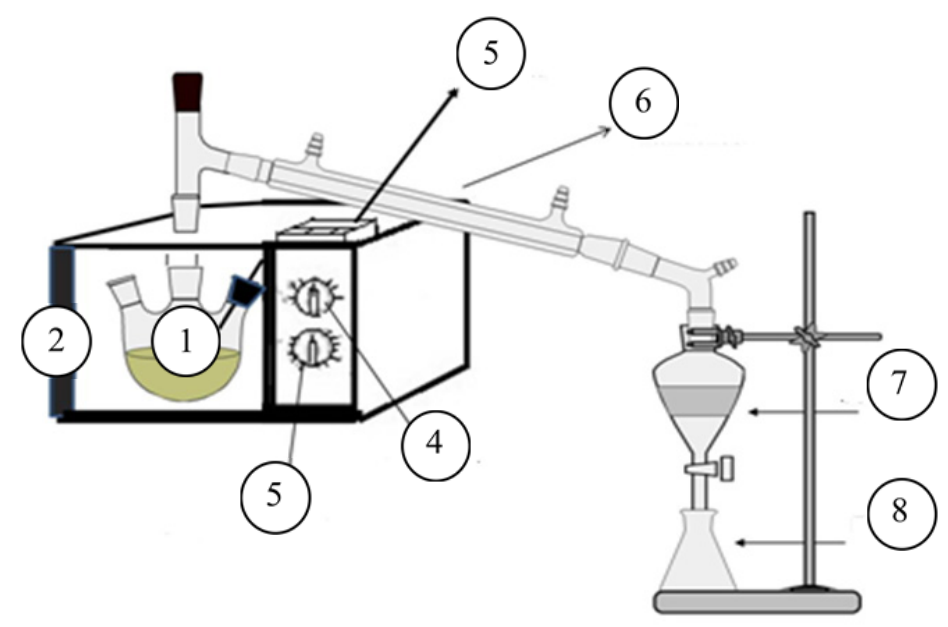

Legend:

1. Tree-neckl flask

2. Macrowave oven

3. Power Setting

4. Time setting

5. Temperature indicator

6. Condensor

7. Separation funnel

8. Erlenmeyer

Figure 1. Experimental Apparatus of Hydro distillation assisted by Microwave

In this experiment, we use two method extraction of oil from cananga flowers. First method we called the conventionally hydro distillation (HD). This type distillation in terms of chemical engineering can also be called leaching process because in this method occurs in the solid solute-making process with the help of water as a solvent and extracted oil join together with water evaporated. The second method is the hydro distillation assisted by microwave (MHD). This method of distillation is like a conventionally hydro distillation with improving heating method that using microwave.

First of all, an amount of flowers and water introduce into the distiller. When the heating system is switch on, the time of experiment begin. The vapor from distiller (distillate) is condensed through a Liebig condenser to form of oil-water mixture. Then oil and water is separated by separation funnel. The water phase is returned into distiller and we get the oil. The oil obtained is dried by adding some anhydrous $\mathrm{Na}_{2} \mathrm{SO}_{4}$, then stored at a temperature of $4{ }^{\circ} \mathrm{C}$ and was analyzed by Gas Chromatography (GC) and GCMS. The operating variables are: flower conditions (fresh and wilted), mass of flowers in distiller (100, 150, and $200 \mathrm{gr}$ ), the size of flowers (chopped, unchopped). 


\section{Results}

\subsection{Effect of Raw Material Conditions on Oil Yield}

The raw materials conditions used are fresh and withered flowers. The condition of fresh cananga flowers are still yellow or chartreuse. Hovewer the withered flower are brownish in color, after withered stored for 4 days. Furthermore, some of flowers were chopped into small size $( \pm 2 \mathrm{~cm})$. Chopping was done because the essential oils in the flower surrounded by oil glands, oil bag or glandular hairs. When the materials are left intact, essential oils can be extracted only when the water vapor through the plant tissue and successfully urged him to the surface. This process aims oil glands that can open as much as possible. Size of place of occurrence of diffusion material thickness will be reduced, so that the oil component will easily diffuse into the surface of the material and the rate of evaporation of volatile oil from the material to be fairly fast. If we want to get a maximum yield of oil, then chopped ingredients should be included in the refinery (Guenther, 1987). In the Figure 2 and 3 can be seen that fresh flowers have a greater oil yield than the flowers withered. This shows that the condition of the material affects the amount of oil yield produced.

The conditions storage of materials before chopping affect the essential oil content in the flowers. Delays in the processing of this material resulted in loss of essential oil content in the material. Several kinds raw material of fresh flower with high water content will lose some essential oils during drying in air. Loss of oil caused by vaporation, oxidation, and other chemical reactions. The process of vaporation effect is not negligible compared to the oxidation process. Vaporation of volatile oil through the walls of plant tissue does not run directly, because the oil must first be transported to the surface of the material through the hydrodifusion process using water as a carrier. However, the flowers and leaves are thin-walled cells, the diffusion process is more possible to occur.

Table 1. The amount of oil obtained from hydro distillation asisted by microwave

\begin{tabular}{lcccc}
\hline \multirow{2}{*}{ Flower conditions } & Mass & \multicolumn{3}{c}{ weight of oil obtained } \\
\cline { 3 - 5 } & $(\mathrm{gr})$ & $264 \mathrm{~W}$ & $400 \mathrm{~W}$ & $600 \mathrm{~W}$ \\
\hline Fresh & 100 & 1.0648 & 1.1965 & --- \\
& 150 & 1.3516 & 1.5222 & 1.6221 \\
\multirow{3}{*}{ Withered } & 200 & 1.6051 & 1.8823 & 1.9702 \\
& 100 & 0.9765 & 1.0755 & --- \\
& 150 & 1.2475 & 1.4296 & 1.5270 \\
& 200 & 1.5146 & 1.7848 & 1.8807 \\
\hline
\end{tabular}

Loss of oil that occurred during the period of withering greater than the loss that occurs during storage of materials. This is because the first stage of the process of withering, plant cells still contain moisture content and the process will hidrodifusi helped bring the oil to the surface and eventually evaporation. However, the compound is vaporized volatile components, not the components of high-boiling compounds. Loss of oil in the material could have been avoided, if the materials are processed immediately or the storage of materials is done at a low temperature dry air and indoor humidity can be arranged (Guenther, 1987).

Based on the data showed that fresh material has a yield greater than the withered material, then for the following discussion is only shown the results of the study were derived from fresh ingredients to see the effect of the length of time observation of cananga oil yield on the three methods. The availability of raw materials too much beyond the capacity distiller, the piles of raw materials (flowers) waiting distillation process, so that this situation will cause the flowers to wither.

The amount of cananga oil obtained is highly influenced by mass of raw materials in distiller. Figures 2 and 3 show the relationship between the oil yield obtained (\%) for various mass of cananga flowers. From those figures shows that the yield always increases significanly with time of distillation until six hours. After six hours the yield is slightly increase, that is because oil content in the cananga flowers has been reduced. For variable mass cananga flowers in distiller $(100,150$, and $200 \mathrm{~g})$, indicate that the less the amount of material in the distiller will faster extraction process or achieve maximum yield (1\%) more quickly. This is related to the density of the material in the distiller and the ratio factor of the amount of material to the water in distiller.

According to figure 2, shows that the total oil yield of fresh flowers after 9 hours distillation are ranging from 0.939 to $0.9836 \%$, while in ffigure 3 shows that the total yield after 9 hours of withered flowers are ranging from 0.8605 to $0.9211 \%$. This suggests that a fresh cananga flower has oil content greater than the withered. 


\subsection{Effect of distillation time on oil yield for hydro distillation assisted by microwave (MHD)}

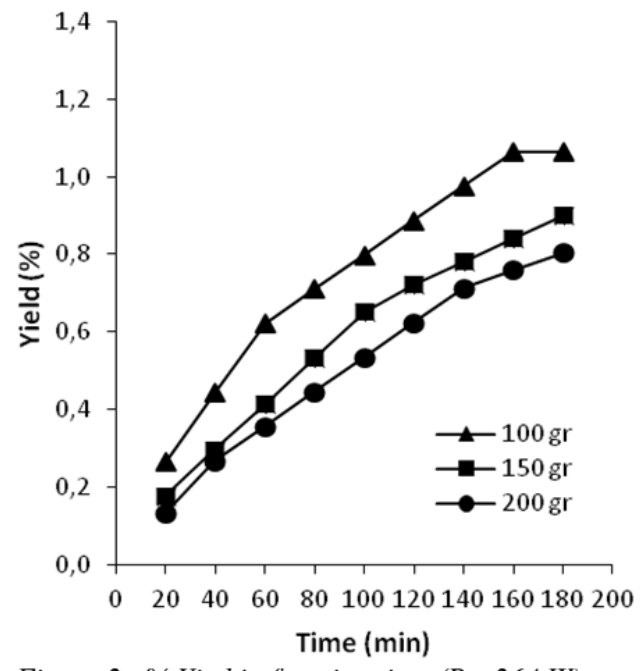

Figure 2. \% Yied in function time $(P=264 \mathrm{~W})$

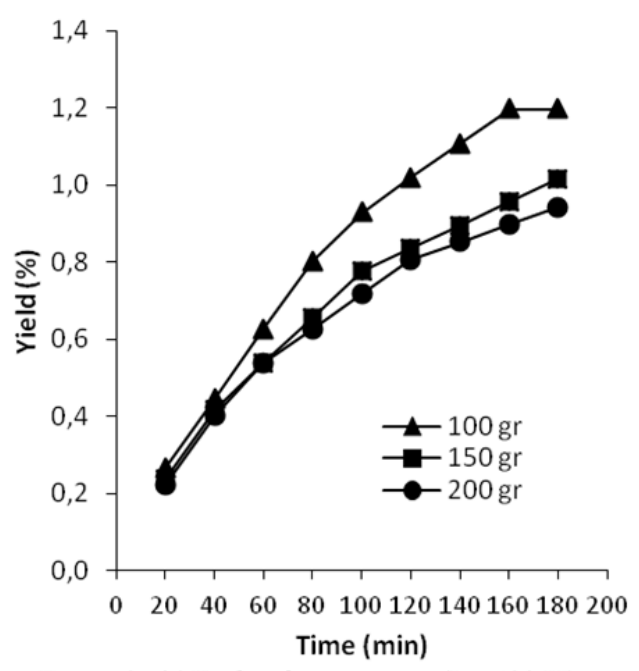

Figure 3. \% Yied in function time $(P=400 \mathrm{~W})$

The amount of cananga oil obtained is highly influenced by mass of raw materials in distiller. Figures 2 and 3 show the relationship between the oil yield obtained (\%) for various mass of cananga flowers. From those figures shows that the yield always increases significanly with time of distillation until 100 minutes. For 100 gr mass of flowers, after 100 minutes the yield is slightly increase, that is because oil content in the cananga flowers has been reduced. But for the mass of 150 and 200 grams at 160 to 180 minutes still continue to produce oil. So if distillatin time is prolonged more than 180 minutes, it will still increase yield until the same with of final yield of a mass of 100 grams.

\subsection{Effect of Mass Content In Distiller on Oil Yield}

From figure 3, it was found that during first 3 hours of the distillation process, the mass of 100 grams gives $\%$ higher yield compared with the mass of 150 and 200 grams. This is due to the calculation of the yield is strongly influenced by the weight of oil recovered and the mass of material used. An increasing number of cananga flowers in distiller will slow extraction process to achieve maximum yield (1\%). This is related to the density of the material in the distiller and the ratio of the number of material factors and water in the distiller.

\subsection{Effect of Microwave Power on Oil Yield}

Microwave power has direct effect on temperature, so that the high power operation raises the temperature the distiller and then increases the oil yield. Microwave power acts as a driving force to break down the plant cell membrane structure, so that the oil can diffuse out and dissolved in a solvent. So the addition of power in general will increase the yield and accelerate the extraction time (Liang et al., 2008). From figure 3 and 4 is generally seen that increasing power produce the highest yield. And at $600 \mathrm{~W}$ produces the highest yield in a shorter time compared to the lower power $(264 \mathrm{~W}$ or $400 \mathrm{~W})$. The operating temperature and the rate of distillation are influenced by the power of microwave. Table 2 shows the average operating temperature recorded during the distillation process depends on the power used.

Table 2. Average operating temperature recorded

\begin{tabular}{ccccc}
\hline Material & Mass & \multicolumn{3}{c}{ Average operating temperature $\left({ }^{\circ} \mathrm{C}\right)$} \\
\cline { 3 - 5 } condtions & $(\mathrm{gr})$ & $264 \mathrm{~W}$ & $400 \mathrm{~W}$ & $600 \mathrm{~W}$ \\
\hline Fresh & 100 & 88 & 112 & 118 \\
& 150 & 89 & 110 & 122 \\
Witherd & 200 & 90 & 108 & 123 \\
& 100 & 92 & 117 & 117 \\
& 150 & 92 & 109 & 128 \\
& 200 & 97 & 107 & 123 \\
\hline
\end{tabular}

From the experimental results it can be seen that the greater the power used, the higher the operating temperature. The rise in temperature is a result of the ability of the material and solvent to absorb energy from the microwaves. 
Measure of the ability to absorb microwaves is called the dielectric constant. Dielectric properties of a material combined with an electromagnetic field were resulting in a conversion of electromagnetic energy into thermal energy (heat). And if the electric field at a uniform volume is considered, then the amount of power or energy (absorbed per unit volume) is proportional to the electric field strength, frequency and dielectric loss factor (Thostenson, 1999).

\subsection{Comparison of Hydro Distillation (HD) and Hydro Distillation Asisted by Microwave (MHD)}

In the previous discussion shows that the fresh flowers have oil yield greater than the flowers withered. Therefore, this data was used to compare between the oil yield obtained from Hydro distillation (HD) and that obtained from hydro distillation asisted by microwave (MHD) as shown in figure 4. From this figure shows that the time distillation to achive maximum yied for hydro distillation asisted by microwave is less than 3 hours. However the time distillation to achive maximum yied for hydro distillation is more than 6 hour. Therefore, the method of hydro distillation asisted by microwave is faster than hydro distillation method to obtain the same oil yield.

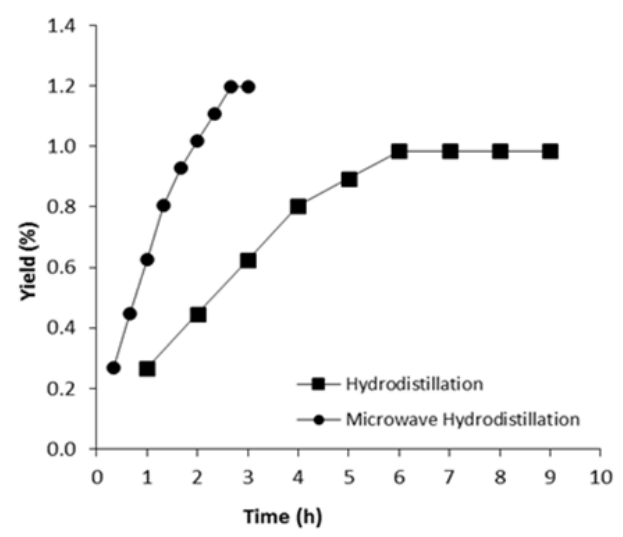

Figure 4. Comparison of oil Yield in time function for Hydro distillation vs Microwave Hyadro distillation (100 g, fresh flowers, power 400W)

From these results, it can be concluded that the use of microwave heating can shorten the time of distillation, can also increase the amount of the yield obtained. This is due to the hydro distillation asisted by microwave method using microwave heating, heat and mass transfer occurs which work in the same direction, namely from the materials to the outside surface of the material and solvent. Microwave energy transfer occurs directly (radiation) to the material and solvent by molecular interactions (polar molecules in the material and solvent) with a microwave electromagnetic field is generated, which in turn is converted into heat energy. So that the effect synergistic of these two combinations accelerates the diffusion process transfer of oil on the surface of flowers (Chemat et al, 2009). In the hydro distillation method using heating mantle heater, energy transfer or heat transfer occurs by conduction, convection and radiation from the walls of the flask (distiller) to the solvent and the surface of the material in the presence of a temperature gradient. As a result, the heating rate is slow. Heat transfer is affected by the thermal conductivity and the temperature difference in the material. While the mass transfer of oil occurs from the inner material to the surface of the material. So the speed of diffusion of the oil to the surface of the material and solvent become slow.

In addition, the nature of microwave heating is volumetric and selective. Volumetric nature in the heating sense occurs directly on the overall volume of the material so that the heating process can be uniform (evenly) and go faster. Heating is selective in the sense of direct microwave radiation can penetrate the distillation flask is transparent (forward microwave), so that the radiation can be directly absorbed by the material and solvent water absorbs microwaves. The heat arising from the material and solvent is affected by the value of the dielectric constant and loss factor dielectric of material and solvent itself. The dielectric constant shows the ability of the molecules in the material to be polarized by the electric field from the outside. While the dielectric loss factor is how much the efficiency of microwave energy that can be absorbed is converted to heat. The solvent used is water which is polar, has a value of dielectric constant $\left(\varepsilon^{\prime}\right)$ is high at 80.4 and has a value of dielectric loss factor of 12.3 at a frequency of $2.45 \mathrm{GHz}$. Solvents that are polar and have a high dielectric constant values can absorb the microwave energy is better than the non-polar solvent. This selective heating is not possible in conventional hydro distillation method (Chemat et al, 2013). 


\subsection{Properties of Cananga Oil Obtained}

According to SNI 06-3949-1995 and EOA, characteristics or physical properties of cananga oil were determined by several parameters, such as specific gravity and refractive index. Therefore, cananga oil obtained, and then measured the density or specific gravity and refractive index. Table 3 shows the physical properties of the oil obtained.

Table 3. Physical and chemical properties of oil obtained in the present work

\begin{tabular}{lcccc}
\hline \multicolumn{1}{c}{ Propertieses } & (SNI/EOA) & $264 \mathrm{~W}$ & $400 \mathrm{~W}$ & $600 \mathrm{~W}$ \\
\hline $\mathrm{S} . g 25^{\circ} \mathrm{C} / 25^{\circ} \mathrm{C}$ & $0,904-0,920$ & $0.9065-0.911$ & $0.9122-0.9157$ & $0.9044-0.9186$ \\
Ref. Index $20^{\circ} \mathrm{C}$ & $1,495-1,505$ & $1.4997-1.5001$ & $1.5001-1.5004$ & $1.4996-1.5000$ \\
Caryophyllene (\%) & - & 17.05 & 18.77 & 17.54 \\
\hline
\end{tabular}

The density associated with content and molecular weight components contained in the cananga oil. The GCMS analysis of cananga oil results obtained indicate that the dominant component of oil are $\beta$-caryophyllene, Benzyl Benzoate, germacrene D, geranyl acetate and Linalool. The greater the weight fraction contained in the oil, the greater the density value (Sastrohamidjojo, 2002). The molecular weight was positively correlated with the density. So the larger the molecular weight of a compound, it will produce a large density. Here's a list of 5 of the dominant component in the cananga oil.

Table 4. The main chemical components of oil obtained in the present work

\begin{tabular}{clccc}
\hline No & Component & MW & Density (gr/ml) & Chemical formula \\
\hline 1. & $\beta$-Caryophyllene & 204,36 & 0,9052 & $\mathrm{C}_{15} \mathrm{H}_{24}$ \\
2. & Benzyl Benzoate & 212,24 & 1,118 & $\mathrm{C}_{14} \mathrm{H}_{12} \mathrm{O}_{2}$ \\
3. & Germacrene D & 204,35 & 0,793 & $\mathrm{C}_{15} \mathrm{H}_{24}$ \\
4. & Geranyl Acetate & 196.29 & 0.916 & $\mathrm{C}_{12} \mathrm{H}_{20} \mathrm{O}_{2}$ \\
5. & Linalool & 154.25 & 0.868 & $\mathrm{C}_{10} \mathrm{H}_{18} \mathrm{O}$ \\
\hline
\end{tabular}

The physical properties of the following are the refractive index. Some factors affecting the refractive index, among others, are the presence of water in the oil content. If there is water content in the oil, it will result a smaller refractive index. This is due to the nature of the water that is easy to refract incoming light. So the essential oil with a large refractive index value is better than the essential oil that has a small refractive index (Guenther, 1987). In this case, the refractive index SNI cananga oil in the range of 1.495 to 1.505 means that if the oil obtained has a value that is included in the EOA range; the oil has a good quality.

According to Table 4, oil analysis results obtained for the refractive index and specific gravity indicates the appropriate value and enters in the range of SNI and EOA. In cananga oil is one of the dominant components of $\beta$-caryophyllene, so as to know which method is better for extraction of oil, then the oil analyzed for levels of $\beta$-caryophyllene. Levels of $\beta$-caryophyllene were used as a reference for how big the method is able to extract a large number of components $\beta$-caryophyllene. Based on the results of the GC analysis, the levels of $\beta$-caryophyllene mainly from hydro distillation asisted by microwave method is $18.77 \%$, while on the lower levels of hydro distillation method is $15.44 \%$. This shows that the method is capable of producing hydro distillation asisted by microwave oil yield higher and able to extract the oil component greater than the hydro distillation method.

\section{Conclusion}

The condition of raw materials affects the amount of oil yield. Oil yield of fresh cananga flower $(0.6251 \%$ $1.1965 \%)$ it's higher than the yield of withered flowers $(0.539-1.0755 \%)$.

The yield obtained increasing with the processing time. The processing time hydro distillation assisted by microwave is shorter than conventionally hydro distillation.

The amount of material in the distiller effect on oil recovery. If more flowers are entered or the denser flowers in the distiller, oil yield obtained lower. Microwave power will affect the temperature of the process. The greater the power will increase the temperature, so that the oil yield obtained greater.

The use of microwave heating for oil extraction can shorten the time and increase the amount of distillate oil 
yield. For hydro distillation method takes up to $7-9$ hours to obtain a yield of $0.9836 \%$, while the hydro distillation asisted by microwave method only takes 3 hours to obtain a yield of $1.1965 \%$ and $0.9837 \%$.

The utilization of microwave does not change to the physical properties of oil. The cananga oil resulting from the hydro distillation assisted by microwave method has a good quality because their specific gravity and refractive index fulfill the quality standard of Indonesian (SNI) and Essential Oil Association (EOA).

\section{Acknowledgments}

The authors would like to thank to the Directorate General of Higher Education, Indonesia for financial support of this research (PUPT - ITS research project).

\section{References}

Anonymous. (2006). Essential Oils of Cananga Business Development. Badan Penelitian dan Pengembangan Daerah Kabupaten Blitar, Blitar.

Chemat, F., Abert-Vian, M., \& Zill-e-Huma, Y. J. (2009). Microwave Assisted Separations. Green Chemistry in Action. Nova Science Publishers. New York. http://dx.doi.org/10.1007/978-1-4614-4830-3

Chemat, F., \& Cravotto, G. (2013). Microwave-assisted Extraction for Bioactive Compounds: Theory and Practice. Springer. New York.

Chemat, F., Sahraoui, N., Abert-Vian, M., Bornard, I., \& Boutekdjiret, C. (2008). Improved Microwave Steam Distillation Apparatus For Isolation Of Essential Oils Comparison With Conventional Steam Distillation, Journal of Chromatography A, 1210, 229-233. http://dx.doi.org/10.1016/j.chroma.2008.09.078

Dalimarta, Setiawan. (2000). Atlas of Indonesian Medicinal Plants, 2. Jakarta, Trubus Agriwidya

Ferhat M, Chemat F, Meklati B, \& Smadja J. (2006). An Improved Microwave Clevenger Apparatus for Distillation of Essential Oils from Orange Peel. Journal of Chromatography A, 1112, 121-126. http://dx.doi.org/10.1016/j.chroma.2005.12.030

Golmakani, M. \& Rezaei, K. (2008). Comparison of microwave-assisted hydro distillation with the traditional hydro distillation method in the extraction of essential oils from Thymus vulgaris L. Food Chemistry, 109, 92-98. http://dx.doi.org/10.1016/j.foodchem.2007.12.084

Guenther, Ernest. (1952). Essentials oil, 5th edition. Van Nostrand Reinhold Company Inc. New York.

Hernani, \& Marwati, T. (2006). Improving the quality of essential oils through a refining process. Center for Agricultural Post harvest Research and Development, Bogor.

Kristiawan, M., Sobolik, V., Al-Haddad, M., \& Allaf, K. (2008a). Effect of pressure-drop rate on the isolation of cananga oil using instantaneous controlled pressure-drop process. Journal of Chemical Engineering and Processin, 47, 66-75. http://dx.doi.org/10.1016/j.cep.2007.08.011

Kristiawan, M., Sobolik, V., \& Allaf, K. (2008b). Isolation of Indonesian Cananga Oil using Multi-cycle Pressure Drop Process. J. Chromatography. A, 1192, 306-318. http://dx.doi.org/10.1016/j.chroma.2008.03.068

Liang, H, Hu, Z., \& Cai, M. (2008). Desirability Function Approach For The Optimization of Microwave-Assisted Extraction of Saikosaponins From Radix Bupleuri. Separation Purification Technology, 61(3), 266-275. http://dx.doi.org/10.1016/j.seppur.2007.10.016

Stashenko, E. E, Jaramillo, B. E., \& Martinez, J. R. (2004). Comparison of different extraction methods for the analysis of volatile secondary metabolites of Lippia Alba (Mill.). N.E. Brown, grown in Colombia, and evaluation of its in vitro antioxidant activity. $J$. Chromatography. A, 1025, 93-99. http://dx.doi.org/10.1016/j.chroma.2003.10.058

Thostenson, E. T., \& Chou, T. W. (1999). Microwave Processing: Fundamentals and Applications. The Journal of Composites Part A: Applied Science and Manufacturing, 30, 1055-1071. http://dx.doi.org/10.1016/S1359-835X(99)00020-2

\section{Copyrights}

Copyright for this article is retained by the author(s), with first publication rights granted to the journal.

This is an open-access article distributed under the terms and conditions of the Creative Commons Attribution license (http://creativecommons.org/licenses/by/3.0/). 